Published in final edited form as:

Environ Int. 2016 September ; 94: 467-472. doi:10.1016/j.envint.2016.06.001.

\title{
In utero exposure to organochlorine pesticides and early menarche in the Avon Longitudinal Study of Parents and Children
}

\author{
Gonza Namulanda a,b, ${ }^{\text {, }}$, Mildred Maisonet ${ }^{\mathrm{c}}$, Ethel Taylor ${ }^{\mathrm{a}}$, W. Dana Flanders ${ }^{\mathrm{a}, \mathrm{d}}$, David Olson ${ }^{\mathrm{a}}$, \\ Andreas Sjodine $^{\mathrm{e}}$, Judith R. Qualters ${ }^{\mathrm{a}}$, John Vena ${ }^{\mathfrak{f}}$, Kate Northstone ${ }^{\mathrm{g}}$, and Luke Naeher ${ }^{\mathrm{a}, \mathrm{b}}$ \\ aDivision of Environmental Hazards and Health Effects, National Center for Environmental Health, \\ Centers for Disease Control and Prevention, 4770 Buford Highway, NE, MS F-60, Atlanta, GA \\ 30341, USA \\ ${ }^{b}$ College of Public Health, University of Georgia, 105 Spear Rd, Athens, GA 30602, USA \\ 'College of Public Health, East Tennessee State University, P O Box 70259, Johnson City, TN \\ 37614, USA \\ ${ }^{\mathrm{d} R o l l i n s}$ School of Public Health, Emory University, 1518 Clifton Road, Atlanta, GA 30322, USA \\ eDivision of Laboratory Sciences, National Center for Environmental Health, Centers for Disease \\ Control and Prevention, 4770 Buford Highway, NE, MS F-17, Atlanta, GA 30341, USA \\ fDepartment of Public Health Sciences, Medical University of South Carolina, 135 Cannon Street \\ Suite 303, MSC 835, Charleston, SC 29425, USA \\ 9School of Social and Community Medicine, University of Bristol, Canynge Hall, 39 Whatley \\ Road, Bristol BS8 2PS, United Kingdom
}

\section{Abstract}

Introduction-Epidemiologic data supporting the role of organochlorine pesticides in pubertal development are limited.

\begin{abstract}
Methods-Using a nested case-control design, serum collected during pregnancy from mothers of 218 girls who reported menarche before 11.5 years of age (cases) and 230 girls who reported menarche at or after 11.5 years of age (controls) was analyzed for 9 organochlorines and metabolites. We analyzed the association between in utero organochlorine concentrations and early menarche using multivariate logistic regression controlling for mother's age at menarche, or mother's prenatal BMI.
\end{abstract}

Results-We did not observe an association between in utero exposure to $\mathrm{HCB}, \beta-\mathrm{HCH}, \Upsilon$ $\mathrm{HCH}, \mathrm{p}, \mathrm{p}^{\prime}$-DDT, p, $\mathrm{p}^{\prime}$-DDE, oxychlordane or trans-nonachlor and early menarche.

Conclusions-This study is the first to examine the association between in utero exposure to $\mathrm{HCB}, \beta-\mathrm{HCH}, \Upsilon-\mathrm{HCH}$, oxychlordane or trans-nonachlor and early menarche. In utero exposure to organochlorine pesticides does not appear to have a role in the timing of menarche in this study.

*Corresponding author at: 4770 Buford Hwy, NE, MS F-60, Atlanta, GA 30341, USA. fos0@cdc.gov (G. Namulanda). 


\section{Keywords}

ALSPAC; Endocrine disrupting compounds; Organochlorine pesticides; Puberty; Menarche

\section{Introduction}

Early menarche, a marker for early puberty, is a risk factor for adverse adult health outcomes including pre- and post-menopausal breast cancer, ovarian cancer, and polycystic ovarian syndrome (Gail et al., 1989; Golub et al., 2008; Moorman et al., 2009; Warner et al., 2013). Previous studies have observed a secular trend towards early puberty in American and European girls (Euling et al., 2008; McDowell et al., 2007; Semiz et al., 2008; Aksglaede et al., 2008; Aksglaede et al., 2009a). There is evidence to suggest a decrease in age at menarche (McDowell et al., 2007; Semiz et al., 2008) and a decrease in age at breast development (Semiz et al., 2008; Aksglaede et al., 2009a). Variability in the onset of puberty has been associated with several genetic and non-genetic factors (Parent et al., 2003). Studies suggest that the declining trend in age at onset of puberty cannot be explained by genetics and obesity alone, and that other environmental factors, such as exposures to endocrine disrupting compounds (EDCs) are involved (Parent et al., 2003; Mouritsen et al., 2010).

Several organochlorine pesticides have been banned or restricted in most countries for decades because of their persistence in the environment and their association with adverse effects in humans and wildlife (U.S. Department of Health and Human Services, Centers for Disease Control and Prevention (CDC), 2009). However, they are still in use especially in developing countries, mainly to control vector-borne diseases (Bergman et al., 2013). Human exposure to organochlorine pesticides occurs primarily through diet, particularly consumption of fatty foods such as meat, fish, and dairy products (U.S. Department of Health and Human Services, Centers for Disease Control and Prevention (CDC), 2009). Organochlorine pesticides can be transferred to the developing fetus through the placenta and to newborns through breast milk. (U.S. Department of Health and Human Services, Centers for Disease Control and Prevention (CDC), 2009) Animal studies suggest that some organochlorine pesticides can act as EDCs by exhibiting weak estrogenic properties associated with early onset of puberty (Clement and Okey, 1972; Gellert et al., 1972). Mechanisms of organochlorine pesticides endocrine activity reported in literature include binding with hormone receptors (Mrema et al., 2013; Raiser et al., 2006), altering hormonal pathways by directly inhibiting enzyme activities responsible for the synthesis of precursors of hormones (Mrema et al., 2013), and stimulating the secretion of the gonadotrophin releasing hormone $(\mathrm{GnRH})$ (Raiser et al., 2006). Exposure to organochlorine pesticides can therefore induce early puberty and eventual early menarche attainment through activation of the hypothalamic GnRH pulse generator or estrogen receptor independent of hypothalamicpituitary axis (Raiser et al., 2006). Additionally, hormone actions during fetal development can be more potent than hormone actions in adults, and the effects permanent (Bergman et al., 2013). It has been suggested that the in utero environment, critical for fetal development, may affect health outcomes later in life such as onset of menarche (Adair, 2001; Kaprio et al., 1995), and that in utero exposure to the estrogenic effect of organochlorine pesticides 
can result in in utero programming of the age at menarche resulting in early menarche (Vasiliu et al., 2004).

Epidemiologic data supporting the role of organochlorine pesticides in pubertal development are limited (Bergman et al., 2013). Reasons include limited capacity of some studies to show temporal relation between exposure and puberty onset, limited studies on the role of background exposures, limited ability to assess confounding, and limited number of organochlorines studied (Crain et al., 2008; Bergman et al., 2013; Buck Louis et al., 2008).

Data on the role of in utero exposures, including organochlorine pesticides, in puberty onset are also limited (Crain et al., 2008; Buck Louis et al., 2008). Using a nested case-control study design, we measured gestational maternal serum concentrations of organochlorine pesticides, a proxy for in utero exposure to organochlorine pesticides, and examined the association with early onset of menarche, as a marker for early puberty, measured prospectively in the population-based Avon Longitudinal Study of Parents and Children (ALSPAC) in Bristol, United Kingdom (U.K.).

\section{Study design and methods}

\subsection{Study population}

Information about ALSPAC and participant recruitment has been described elsewhere (Fraser et al., 2013; Boyd et al., 2013). Pregnant women residing in Bristol and the surrounding area, in the South west of England, were eligible to participate if their expected delivery date was between and including the dates 1st April, 1991 and 31st December, 1992. The total sample size was 15,247 pregnancies resulting in 14,775 live births. A fully searchable data dictionary is available at http://www.bris.ac.uk/alspac/researchers/dataaccess/data-dictionary/.

The selection of cases and controls for the nested case-control study has already been described in detail (Christensen et al., 2011). Briefly, from the cohort of 14,775 live births, 3682 singleton girls returned at least 2 'Growing and Changing' puberty questionnaires between the ages of 8 to 13 years, which recorded self-reported age at onset of menarche and month and year of first period. This questionnaire was sent to the study participants every year from ages 8 to 17 (except at age 12). The puberty questionnaire is available at http://www.bristol.ac.uk/media-library/sites/alspac/migrated/documents/ques-cb16a-mumand-daughter-at-8.pdf. Girls were ranked according to age at menarche, and 11.5 years was selected as the cut-off for earlier age at menarche to satisfy sample size and power needed for the case-control study. The median age at onset of menarche (95\% confidence interval) for the larger cohort of girls $(n=3938)$ that returned at least one puberty questionnaire was reported as 12.87 years (10.82-12.91) (Christensen et al., 2010). Of the 3682 girls who returned two or more questionnaires, 218 had earlier menarche, defined as first menstruation before 11.5 years (cases) and also had a maternal serum sample that could be analyzed. A random sample of 230 controls who had menarche at 11.5 years or older and had a maternal serum sample that could be analyzed, was selected from the same group of 3682 singleton girls. Serum samples were collected from the mothers during routine antenatal care at random times during pregnancy (1991-1992) (Fraser et al., 2013; Boyd et al., 2013). The serum samples were banked at the University of Bristol at $+4{ }^{\circ} \mathrm{C}$ for $0-4$ days after initial 
collection (or frozen at $-20^{\circ} \mathrm{C}$ for $0-6$ days after initial collection), then aliquoted and refrozen at $-20^{\circ} \mathrm{C}$ until analysis. Human subject protection was assessed and approved by the ALSPAC Law and Ethics Committee, the Local Research Ethics Committees, and the Centers for Disease Control and Prevention (CDC) Institutional Review Board (Christensen et al., 2011).

\subsection{Exposure assessment}

Maternal serum samples for this study were sent to the National Center for Environmental Health (NCEH), CDC in 2008 for analysis. The NCEH laboratory measured the following 9 organochlorine pesticide analytes by gas chromatography isotope dilution high resolution mass spectrometry (Sjodin et al., 2004): Hexachlorobenzene (HCB), isomers of hexachlorocyclohexane (i.e., $\beta$-hexachlorocyclo-hexane $(\beta-\mathrm{HCH})$ and $\Upsilon$ hexachlorocyclohexane ( $\Upsilon$-HCH/Lindane)), chlorodane-related pesticides (i.e., oxychlorodane (oxychlor) and trans-nonachlor (T-nona)), Mirex, and isomers of DDT (i.e., 2,2-bis(4-chlorophenyl)-1,1-dichloroethene (p, $\mathrm{p}^{\prime}$-DDE); 2-(4-chlorophenyl)-2-(2chlorophenyl)-1,1,1-trichloroethane (o, $\mathrm{p}^{\prime}$-DDT); and 2,2-bis(4-chlorophenyl)-1,1,1trichloroethane ( $\mathrm{p}, \mathrm{p}^{\prime}$-DDT)). Concentrations were reported on a whole weight basis (pg/g serum) and lipid-adjusted basis (ng/g lipid) corrected for total serum lipid levels. The total serum lipid levels were calculated from the measured concentration of total cholesterol and triglycerides using the equation 'Total lipid $(\mathrm{g} / \mathrm{L})=2.27 \times$ Total Cholesterol $(\mathrm{g} / \mathrm{L})+$ Total triglycerides $+0.623^{\prime} 0.623^{\prime}$ as reported in Phillips et al. (1989) The limit of detection (LOD) was defined as the highest of (i) three times the standard deviation of blanks analyzed in parallel with the unknowns and (ii) the lowest calibration point having a signal to noise ratio greater than three (Sjodin et al., 2004).

Some of the organochlorine values reported were below the LOD, therefore, in order to calculate the median, and 25th and 75th percentiles, we used survival analysis methods (proc Lifetest for non-parametric estimation) with SAS software version 9.3 (SAS Institute Inc., Cary, NC, USA) to account for left censored values, i.e., <LOD (Gillespie et al., 2010). In order to use methods intended for right-censored data on left-censored data, we transformed the data by subtracting a constant from the pesticide concentrations, and after calculations, transformed the data back to the original units. We calculated the median, and 25th and 75th percentiles for lipid-adjusted values for organochlorines detected $x_{\mathrm{LOD}}$ in $>50 \%$ of the study participants. For organochlorines detected in $<50 \%$ of the study participants we only calculated the percent $>$ LOD.

\subsection{Association between early menarche and organochlorine serum concentrations}

To assess the association between early menarche and organochlorine serum concentrations, we substituted values $\angle \mathrm{LOD}$ with $\mathrm{LOD} / \sqrt{2}$ and natural $\log$ transformed the values before analysis for organochlorines measured in $>50 \%$ of study participants. Serum sample weights for this study ranged from $0.12 \mathrm{~g}$ to $1.23 \mathrm{~g}$, and smaller samples $(<0.4 \mathrm{~g})$ tended to have higher LODs (i.e., less ability to detect low levels of organochlorine concentrations) (U.S. Department of Health and Human Services, Centers for Disease Control and Prevention (CDC), 2009). These higher LODs could bias analyses when substituting values <LOD with 
LOD $/ \sqrt{2}$; therefore, we plotted the lipid-adjusted LOD against the sample weight (see supplement), selected an LOD cut-off of $13 \mathrm{ng} / \mathrm{g}$ lipid, and excluded participants with a lipid-adjusted LOD $\geq 13 \mathrm{ng} / \mathrm{g}$ lipid (Sjodin et al., 2014). Using this criteria, we removed 10 study participants from the analysis of $\mathrm{p}, \mathrm{p}^{\prime}$-DDT, which was the only organochlorine evaluated that had values $<$ LOD with LOD $\geq 13 \mathrm{ng} / \mathrm{g}$ lipid.

We also dichotomized exposure to these organochlorines as $\succeq$ median or $<$ median using the distribution of the controls. For organochlorines measured in $<50 \%$ of study participants we dichotomized exposure as "yes" for values measured $\mathbb{L} \mathrm{OD}$ and "No" for values <LOD.

We identified a priori, the following 10 covariates that could be associated with the exposure or outcome, and assessed them for potential confounding: mother's race (White or nonWhite) (McDowell et al., 2007; Biro et al., 2010; Rubin et al., 2009), mother's pre-natal body mass index (BMI) (<18.5 (underweight), 18.5-24.9 (normal), 25-29.9 (over-weight), or $\geq 30$ (obese)) (Rubin et al., 2009), mother's age at menarche (8-11, 12-14, or $\geq 15$ years) (Rubin et al., 2009), mother's age at delivery ( $<20,20-24,25-29,30-39$, or $\geq 40$ years) (Schade and Heinzow, 1998), socio-economic status (using mother's education as a proxy) (certificate of secondary education (CSE)/none, vocational, O-level, A-level, or degree) (Parent et al., 2003), child's birth order (first born, second born, or third born or later) (Rubin et al., 2009; Schade and Heinzow, 1998), child's BMI at age $7\left(\mathrm{Kg} / \mathrm{m}^{2}\right)$ (Biro et al., 2010; Aksglaede et al., 2009b), duration of breast feeding (never, <6, or $\geq 6$ months) (Schade and Heinzow, 1998), child's birth weight (<2500 or $\geq 2500$ g) (Ruder et al., 2010), and gestation trimester when serum sample was collected ( $₫ 2,13-28$, or $\geq 29$ weeks) (Longnecker et al., 1999).

We used logistic regression to analyze the association between early menarche and organochlorine pesticide exposure. We included potential confounders with p-value (p) $<0.25$ (Mickey and Greenland, 1989) in the multivariate logistic model.

\section{Results}

Compared to the controls, cases were more likely to have a mother who had onset of menarche between the ages of 8 and 11 years, or who was overweight or obese before pregnancy (Table 1). Cases were also more likely to be a first born child or have a mother who was of non-white race, compared to the controls. Cases had significantly higher prepubertal BMIs at age 7 compared to controls $(\mathrm{p}<0.0001)$.

$\mathrm{HCB}, \beta-\mathrm{HCH}, \mathrm{p}, \mathrm{p}^{\prime}$-DDE, and $\mathrm{p}, \mathrm{p}^{\prime}$-DDT were detected above the LOD in $>50 \%$ of the study participants while T-nona, oxychlor, $\Upsilon$-HCH, o, $\mathrm{p}^{\prime}$-DDT and mirex were detected above the LOD in $<50 \%$ of the study participants (Table 2). HCB was the most frequently detected organochlorine (100\%) followed by p, $\mathrm{p}^{\prime}$-DDE $(99.8 \%), \beta-\mathrm{HCH}(98.1 \%), \mathrm{p}, \mathrm{p}^{\prime}$-DDT (92.5\%), T-nona (31.2\%), oxychlor (26.9\%), $\Upsilon$-HCH (20.8\%), o, p'-DDT (1.4\%) and mirex $(0.5 \%)$. Because of low detection $>\mathrm{LOD}, \mathrm{o}, \mathrm{p}^{\prime}$-DDT and mirex were not included in further analyses. There were no significant differences in exposure to any of the organochlorine pesticide concentrations between cases and controls (Table 2). We used lipid-adjusted 
organochlorine concentrations in all our analyses (See supplement for tables using whole weight concentrations).

We did not find an association between in utero exposure to organochlorine pesticides and early menarche (Tables 3, 4 and 5). We examined the organochlorine pesticide and early menarche association using 3 lipid-adjusted variables for $\mathrm{HCB}, \beta-\mathrm{HCH}, \mathrm{p}, \mathrm{p}^{\prime}-\mathrm{DDE}$, and $\mathrm{p}, \mathrm{p}$ '-DDT: log transformed continuous, dichotomized (<median or ๖median), and categorized into quartiles. We dichotomized lipid-adjusted T-nona, oxychlor, and $\Upsilon$-HCH concentrations as $<$ LOD or $\mathbb{L}_{\mathrm{LOD}}$. In the unadjusted models, the odds of early menarche for each unit increase of logged organochlorine pesticide concentration (odds ratio (OR)) and $95 \%$ confidence interval $(\mathrm{CI})$ were $\mathrm{OR}=1.06(95 \% \mathrm{CI}: 0.67,1.68)$ for $\mathrm{HCB}, \mathrm{OR}=0.91(95 \% \mathrm{CI}$ : $0.64,1.29)$ for $\beta-\mathrm{HCH}, \mathrm{OR}=0.91(95 \%$ CI: $0.70,1.19)$ for $\mathrm{p}, \mathrm{p}^{\prime}-\mathrm{DDE}$ and $\mathrm{OR}=1.06(95 \%$ CI: $0.72,1.54$ ) for $\mathrm{p}, \mathrm{p}^{\prime}$-DDT (Table 3 ). In the adjusted multivariate models, all odds ratios were <1; OR $=0.93$ (95\% CI: $0.58-1.50$ ) for $\mathrm{HCB}, \mathrm{OR}=0.85$ (95\% CI: $0.59-1.22$ ) for $\beta$ $\mathrm{HCH}$, and $\mathrm{OR}=0.97(95 \% \mathrm{CI}: 0.65-1.42)$ for $\mathrm{p}, \mathrm{p}^{\prime}$-DDT. None of the unadjusted or adjusted associations were significant ( $95 \% \mathrm{CI}$ included the null value, 1 , and $\mathrm{p}$ value $>0.05$ ). The results were similar for $\mathrm{HCB}$ and $\beta-\mathrm{HCH}$ exposure dichotomized as $\searrow$ median or <median (Table 4). However, the direction of association changed for DDE (unadjusted OR $=1.23$ (95\% CI: 0.80-1.85)) and DDT (adjusted OR $=1.13$ (95\% CI: 0.74-1.73)). None of the associations were significant. As a sensitivity analysis, we categorized exposure to these organochlorines in quartiles ( $<25$ th, $\geq 25$ th $-<50$ th, $\geq 50$ th $-<75$ th, or $\geq 75$ th percentiles). The odds of early menarche for in utero exposure to $\geq 75$ th percentile compared to $<25$ th percentile (reference) remained similar to those presented in Table 3, except the unadjusted odds for $\mathrm{p}, \mathrm{p}^{\prime}$-DDT which was $<1$ (Table 5). For exposure to oxychlor, T-nona and $\Upsilon$-HCH dichotomized as $\Perp_{L} O D$ or $<$ LOD, the unadjusted and adjusted odds ratios were $<1$ except for T-nona with unadjusted odds ratio $=1.05(95 \%$ CI: 0.69-1.62) (Table 4). We did not examine the association between early menarche and o, $\mathrm{p}^{\prime}$-DDT or mirex because very few participants had detected values $>$ LOD ( $1.4 \%$ and $0.5 \%$ respectively).

We also performed a sensitivity analysis using different confounders. We selected a priori 4 covariates typically used in other puberty studies: mother's age at menarche, mother's age at delivery, mother's education and duration of breastfeeding. For the early menarche-logged organochlorine pesticide exposure association analysis, the results were similar to those presented in Table 3, but the direction of adjusted odds of $\mathrm{p}, \mathrm{p}^{\prime}$-DDT changed to $>1$ (data not shown). For dichotomous exposure, the results were similar to those presented in Table 4 (data not shown). None of the associations were significant.

We also explored the organochlorine and early menarche association, only in the subset of controls, using linear regression analysis, and did not find any association (see supplement).

\section{Discussion}

\subsection{Puberty}

This study is the first to analyze the association between in utero exposure to $\mathrm{HCB}, \beta-\mathrm{HCH}$, $\Upsilon$-HCH, oxychlordane or T-nonachlor and early menarche in girls. Two previous studies have analyzed the association between in utero exposure to DDE and pubertal development 
(Vasiliu et al., 2004; Gladen et al., 2000). Similar to the Gladen et al. study in girls born between 1978 and 1982 (Gladen et al., 2000), our study did not find an association between in utero exposure to DDE, or other organochlorine pesticides, and age at menarche. The lipid-adjusted median DDE concentration for the Gladen et al. (2000) study population was $2400 \mathrm{ppb}$, while the lipid-adjusted median DDE concentration for our study population was $311 \mathrm{ng} / \mathrm{g}$ (ppb). In comparison, a study by Vasiliu et al. (2004) among children born between 1950 and 1980 found that an increase of $15 \mu \mathrm{g} / \mathrm{l}$ of DDE in utero reduced age at menarche by one year; however, this association was no longer significant after controlling for BMI at age of menarche. The study authors hypothesized that the estrogenic effect of DDE in utero could result in earlier age at menarche as supported by findings in other studies that reported lower age at menarche in female twins compared to girls exposed to male co-twins in utero (Kaprio et al., 1995; Vasiliu et al., 2004). The population in the Vasiliu et al. study may have been exposed to potentially higher amounts of DDE due to high maternal consumption of contaminated fish in the Great Lakes. The median in utero DDE concentration was $7 \mu \mathrm{g} / \mathrm{l}$ for girls who attained menarche between the ages of 9 and 11 years, $4.2 \mu \mathrm{g} / \mathrm{l}$ and $3.8 \mu \mathrm{g} / \mathrm{l}$ for girls who attained menarche between the ages 12-14 years and 14-17 years respectively. The study did not report lipid-adjusted concentrations. This previous study was smaller $(\mathrm{N}=$ 151), with only 22 girls with age at onset of menarche from 9-11 years (Vasiliu et al., 2004). In this present study, we were also able to assess additional characteristics of the mother and child for confounding potential, e.g., child's pre-pubertal BMI, collected prospectively through puberty.

Our study analyzed the association between in utero exposure to organochlorine pesticides and age at menarche, but not onset of puberty which is typically represented by a Tanner stage 2 of breast development. Even though in utero exposure to organochlorine pesticides does not appear to impact menarche timing in our study, we should not rule out the possibility of an impact on age at puberty onset. The fact that the timing of onset of puberty in girls seems to be decreasing (Euling et al., 2008; Aksglaede et al., 2009a) while the timing of menarche recently appears to be more stable (Juul et al., 2006) lends support to the exploration of such associations.

\subsection{Exposure}

U.K. population exposure studies with serum samples collected from 2001-2003 showed $>50 \%$ lower levels of $\mathrm{p}, \mathrm{p}^{\prime}$-DDT, p, $\mathrm{p}^{\prime}$-DDE, HCB and $\beta$-HCH median concentrations compared to our study (Kalantzi et al., 2004; Thomas et al., 2006). This decreasing trend has also been observed in other developed countries such as the United States where these pesticides are no longer in use or have been restricted (U.S. Department of Health and Human Services, Centers for Disease Control and Prevention (CDC), 2009). DDT was banned in the United Kingdom in 1986 (Rogan and Chen, 2005). Twelve persistent organic pollutants including DDT, HCB and chlordane were banned or restricted globally in a 2004 treaty at the Stockholm Convention on Persistent Organic Pollutants, and $\mathrm{HCH}$ was one of the 9 pollutants added to the list in a 2009 amendment (The Stockholm Convention, 2008). However, some organochlorines, such as DDT, are still in use especially in developing countries, mainly for vector-borne disease control (Bergman et al., 2013). 


\subsection{Study limitations}

This study may be subject to selection bias due to differences in characteristics of participants who did not respond to the puberty questionnaire and therefore were excluded from this study (Christensen et al., 2011). The removal of some records from the analysis of $\mathrm{p}, \mathrm{p}^{\prime}$-DDT could bias the study results; however, when we included all the samples of $\mathrm{p}, \mathrm{p}^{\prime}$ DDT in the analyses, the results were similar. We excluded from our analyses records with missing covariate data and lipid-adjusted values of the organochlorine concentrations; this exclusion could also bias our results. However, when we imputed values for missing data using SAS 9.3 and re-ran the analyses, the results remained similar to those presented in Tables 3 and 4 . The study may be underpowered to detect associations between gestational organochlorine pesticide concentrations and early menarche due to a small sample size.

\section{Conclusion}

This is the first study to examine the association between in utero exposure to $\mathrm{HCB}, \beta-\mathrm{HCH}$, $\Upsilon-\mathrm{HCH}$, oxychlordane or trans-nonachlor and early menarche. In utero exposure to organochlorine pesticides appears to have no role in the timing of menarche in this study. Since populations are often exposed to combinations of pesticides and other chemicals in the environment, future work will include examining the effects of multiple EDC exposures, including organochlorine pesticides, on onset of puberty in the ALSPAC cohort.

\section{Supplementary Material}

Refer to Web version on PubMed Central for supplementary material.

\section{Acknowledgments}

We are extremely grateful to all the families who took part in this study, the midwives for their help in recruiting them, and the whole ALSPAC team, which includes interviewers, computer and laboratory technicians, clerical workers, research scientists, volunteers, managers, receptionists and nurses. The UK Medical Research Council and the Wellcome Trust (Grant ref.: 102215/2/13/2) and the University of Bristol provide core support for ALSPAC. This work was specifically funded by Centers for Disease Control and Prevention. The findings and conclusions in this report are those of the authors and do not necessarily represent the views of the Centers for Disease Control and Prevention.

\section{Appendix A. Supplementary data}

Supplementary data to this article can be found online at http://dx.doi.org/10.1016/j.envint. 2016.06.001.

\section{References}

Adair L. Size at birth predicts age at menarche. Pediatrics. 2001 Apr.107(4)

Aksglaede L, Juul A, Olsen LW, Sorensen TIA. Age at puberty and the emerging obesity epidemic. PLoS One. 2009b Dec.4(12):e8450. [PubMed: 20041184]

Aksglaede L, Olsen LW, Sørensen TI, Thorkild IA, Juul A. Forty years trends in timing of pubertal growth spurt in 157,000 Danish school children. PLoS One. 2008 Jul 16.3(7):e2728. [PubMed: 18628945] 
Aksglaede L, Sørensen K, Petersen JH, Skakkebaek NE, Juul A. Recent decline in age at breast development: the Copenhagen Puberty Study. Pediatrics. 2009a May 1; 123(5):e932-e939. [PubMed: 19403485]

Bergman, A.Heindel, JJ.Jobling, S.Kidd, KA., Zoeller, RT., editors. State of the Science of Endocrine Disrupting Chemicals - 2012. United Nations Environment Programme \& World Health Organisation; Geneva: 2013.

Biro FM, Galvez MP, Greenspan PA, et al. Pubertal assessment method and baseline characteristics in a mixed longitudinal study of girls. Pediatrics. 2010 Sep; 126(3):e583-e590. [PubMed: 20696727]

Boyd A, Golding J, Macleod J, et al. Cohort profile: the 'children of the 90s' - the index offspring of the Avon Longitudinal Study of Parents and Children. Int J Epidemiol. 2013 Feb; 42(1):111-127. [PubMed: 22507743]

Buck Louis GM, Gray LE Jr, Marcus M, et al. Environmental factors and puberty timing: expert panel research needs. Pediatrics. 2008 Feb; 121(Supplement 3):S192-S207. [PubMed: 18245512]

Christensen KY, Maisonet M, Rubin R, et al. Pubertal pathways in girls enrolled in a contemporary British cohort. Int J Pediatr. 2010

Christensen KY, Maisonet M, Rubin C, et al. Exposure to polyfluoroalkyl chemicals during pregnancy is not associated with offspring age at menarche in a contemporary British cohort. Environ Int. 2011; 37(1):129-135. [PubMed: 20843552]

Clement JG, Okey AB. Estrogenic and anti-estrogenic effects of DDT administered in the diet to immature female rats. Can J Physiol Pharmacol. 1972 Oct; 50(10):971-975. [PubMed: 4637185]

Crain D, Janssen S, Edwards TM, et al. Female reproductive disorders: the roles of endocrine disrupting compounds and developmental timing. Fertil Steril. 2008 Oct; 90(4):911-940. [PubMed: 18929049]

Euling SY, Herman-Giddens ME, Lee PA, et al. Examination of US puberty-timing data from 1940 to 1994 for secular trends: panel findings. Pediatrics. 2008 Feb; 121(Suppl 3):S172-S191. [PubMed: 18245511]

Fraser A, Macdonald-Wallis C, Tilling K, et al. Cohort profile: the Avon Longitudinal Study of Parents and Children: ALSPAC mothers cohort. Int J Epidemiol. 2013 Feb; 42(1):97-110. [PubMed: 22507742]

Gail MH, Brinton LA, Byar DP, et al. Projecting individualized probabilities of developing breast cancer for white females who are being examined annually. J Natl Cancer Inst. 1989 Dec 20; 81(24):1879-1886. [PubMed: 2593165]

Gellert RJ, Heinrichs WL, Swerdloff RS. DDT homologues: estrogen-like effects on the vagina, uterus and pituitary of the rat. Endocrinology. 1972 Oct; 91(4):1095-1100. [PubMed: 5051333]

Gillespie BW, Chen QX, Reichert H, et al. Estimating population distributions when some data are below a limit of detection by using a reverse Kaplan-Meier estimator. Epidemiology. 2010; 21:S64-S70. [PubMed: 20386104]

Gladen BC, Ragan NB, Rogan WJ. Pubertal growth and development and prenatal and lactational exposure to polychlorinated biphenyls and dichlorodiphenyl dichloroethene. J Pediatr. 2000 Apr; 136(4):490-496. [PubMed: 10753247]

Golub MS, Colluman GW, Foster PM, et al. Public health implications of altered puberty timing. Pediatrics. 2008 Feb; 121(Suppl 3):S218-S230. [PubMed: 18245514]

Juul A, Teilmann G, Scheike T, et al. Pubertal development in Danish children: comparison of recent European and US data. Int J Androl. 2006; 29:247-255. [PubMed: 16466546]

Kalantzi OI, Martin FL, Thomas GO, et al. Different levels of polybrominated diphenyl ethers (PBDEs) and chlorinated compounds in breast milk from two U.K. regions. Environ Health Perspect. 2004 Jul; 112(10):1085-1091. [PubMed: 15238282]

Kaprio J, Rimpela A, Winter T, Viken R, et al. Common genetic influences on BMI and age at menarche. Hum Biol. 1995 Oct.:739-753. [PubMed: 8543288]

Longnecker MP, Klebanoff MA, Gladen BC, Berendes HW. Serial levels of serum organochlorines during pregnancy and postpartum. Arch Environ Health. 1999 Mar-Apr;54(2):110-114. [PubMed: 10094288] 
McDowell MA, Brody DJ, Hughes JP. Has age at menarche changed? Results from the National Health and Nutrition Examination Survey (NHANES) 1999-2004. J Adolesc Health. 2007 Mar; 40(3):227-231. [PubMed: 17321422]

Mickey RM, Greenland S. The impact of confounder selection criteria on effect estimation. Am J Epidemiol. 1989 Jan; 129(1):125-137. [PubMed: 2910056]

Moorman PG, Palmieri RT, Akushevich L, Berchuck A, Schildkraut JM. Ovarian cancer risk factors in African-American and White women. Am J Epidemiol. 2009 Sep 1; 170(5):598-606. [PubMed: 19605513]

Mouritsen A, Aksglaede K, Sorensen K, et al. Hypothesis: exposure to endocrine-disrupting chemicals may interfere with timing of puberty. Int J Androl. 2010 Apr; 33(2):346-359. [PubMed: 20487042]

Mrema E, Rubino FM, Brambilla G, et al. Persistent organochlorinated pesticides and mechanisms of their toxicity. Toxicology. 2013 May.307:74-88. [PubMed: 23219589]

Parent AS, Teilmann G, Juul A, Skakkebaek NE, Toppari J, Bourguignon JP. The timing of normal puberty and the age limits of sexual precocity: variations around the world, secular trends, and changes after migration. Endocr Rev. 2003 Oct; 24(5):668-693. [PubMed: 14570750]

Phillips DL, Pirkle JL, Burse VW, et al. Chlorinated hydrocarbon levels in human serum: effects of fasting and feeding. Arch Environ Contam Toxicol. 1989; 18:495-500. [PubMed: 2505694]

Raiser G, Toppari J, Parent A, Bourguignon J. Female sexual maturation and reproduction after prepubertal exposure to estrogens and endocrine disrupting chemicals: a review of rodent and human data. Mol Cell Endocrinol. 2006 Jul.254-255:187-201.

Rogan WJ, Chen A. Health risks and benefits of bis(4-chlorophenyl)-1,1,1-trichloroethane (DDT). Lancet. 2005 Sep; 366(9487):763-773. [PubMed: 16125595]

Rubin C, Maisonet M, Kieszak S, Monteilh C, Holmes AK, Flanders D, et al. Timing of maturation and predictors of menarche in girls enrolled in a contemporary British cohort. Paediatr Perinat Epidemiol. 2009; 23:492-504. [PubMed: 19689500]

Ruder E, Hartman T, Rovine M, Dorgan J. Birth characteristics and age at menarche: results from the dietary intervention study in children (DISC). Cancer Causes Control. 2010 Sep; 21(9):13791386. [PubMed: 20495859]

Schade G, Heinzow B. Organochlorine pesticides and polychlorinated biphenyls in human milk of mothers living in northern Germany: current extent of contamination, time trend from 1986 to 1997 and factors that influence the levels of contamination. Sci Total Environ. 1998:31-39.

Semiz S, Kurt F, Kurt DT, Zencir M, Sevinc O. Pubertal development of Turkish children. J Pediatr Endocrinol Metab. 2008 Oct; 21(10):951-961. [PubMed: 19209617]

Sjodin A, Jones RS, Lapeza CR, Focant JF, McGahee EE 3rd, Patterson DG Jr. Semi-automated highthroughput extraction and cleanup method for the measurement of polybrominated diphenyl ethers, polybrominated biphenyls, and polychlorinated biphenyls in human serum. Anal Chem. 2004 Apr 1; 76(7):1921-1927. [PubMed: 15053652]

Sjodin A, Schecter A, Jones R, et al. Polybrominated diphenyl ethers, 2, 2, 4, 4, 5, 5 hexachlorobiphenyl (PCB-153), and p, $\mathrm{p}^{\prime}$-dichlorodiphenyldichloroethylene (p,p-DDE) concentrations in sera collected in 2009 from Texas children. Environ Sci Technol. 2014 Jul 15.48:8196-8202. [PubMed: 24911286]

The Stockholm Convention. The 12 initial POPs under the Stockholm Convention. 2008. http:// chm.pops.int/TheConvention/ThePOPs/The12InitialPOPs/tabid/296/Default.aspx (Accessed February, 2014)

Thomas GO, Wilkinson M, Hodson S, Jones KC. Organohalogen chemicals in human blood from the United Kingdom. Environ Pollut. 2006 May; 141(1):30-41. [PubMed: 16236409]

U.S. Department of Health and Human Services, Centers for Disease Control and Prevention (CDC). The fourth national report on human exposure to environmental chemicals. 2009D. http:// www.cdc.gov/exposurereport/ (Accessed February, 2014)

Vasiliu O, Muttineni J, Karmaus W. In utero exposure to organochlorines and age at menarche. Hum Reprod. 2004 Jul; 19(7):1506-1512. [PubMed: 15131079] 
Warner ET, Colditz GA, Palmer JR, Partridge AH, Rosner BA, Tamimi RM. Reproductive factors and risk of premenopausal breast cancer by age at diagnosis: are there differences before and after age 40? Breast Cancer Res Treat. 2013 Nov; 142(1):165-175. [PubMed: 24136668] 


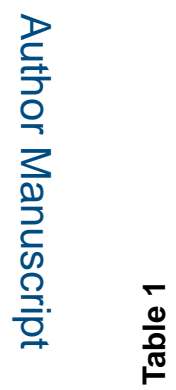

름

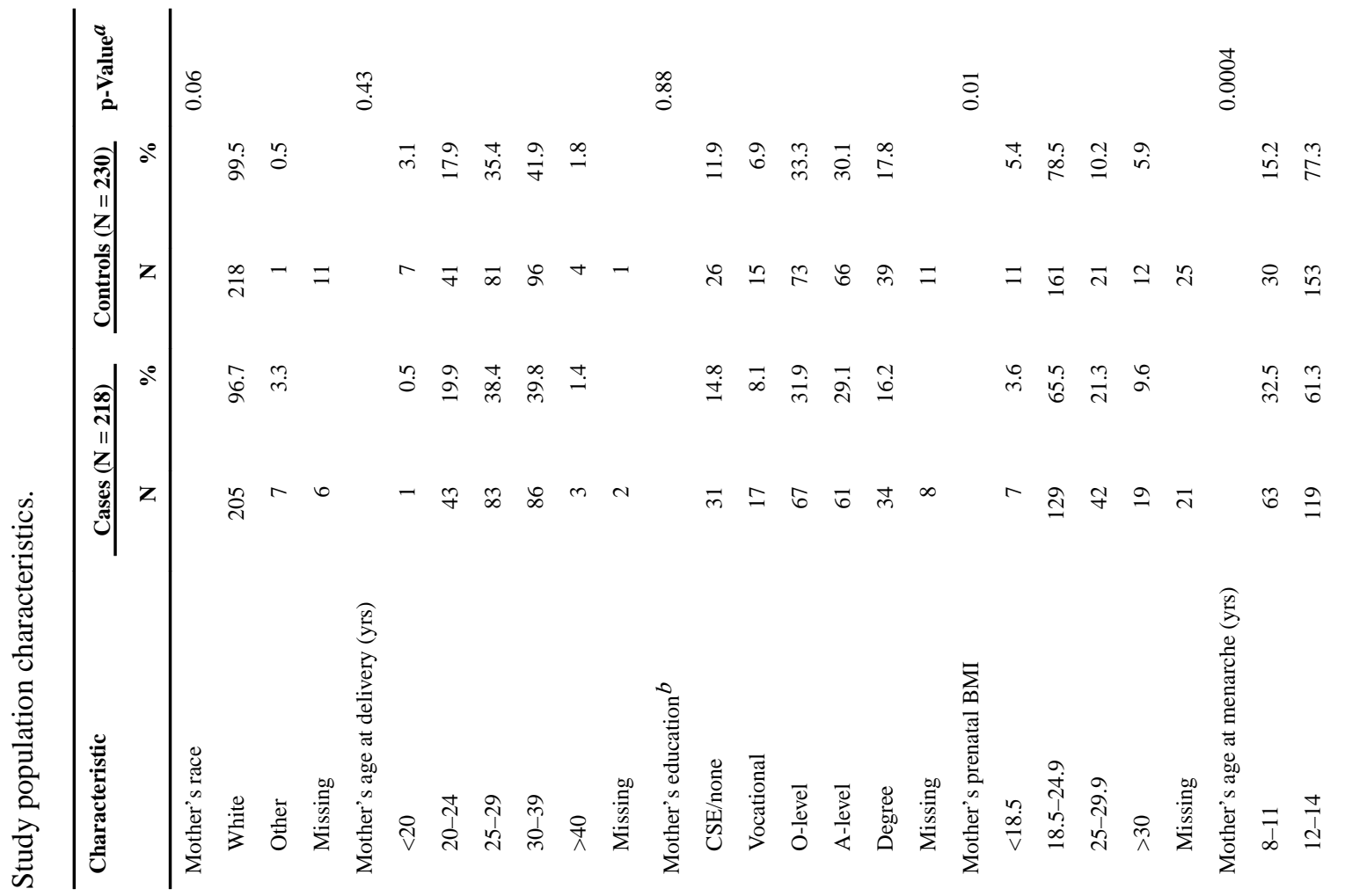

Environ Int. Author manuscript; available in PMC 2017 November 13. 
Namulanda et al.

Page 13

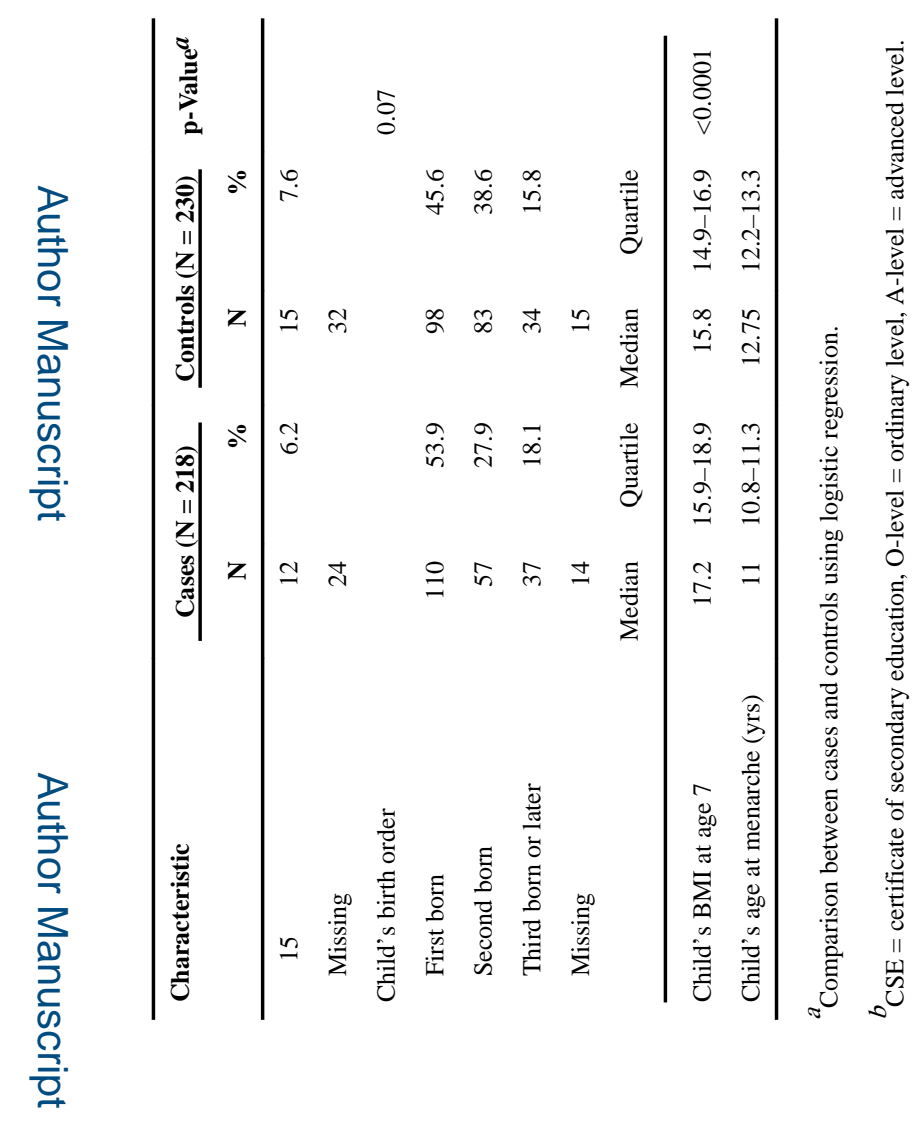

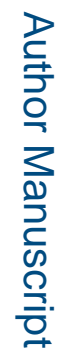

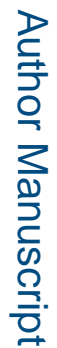

Environ Int. Author manuscript; available in PMC 2017 November 13. 


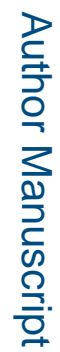

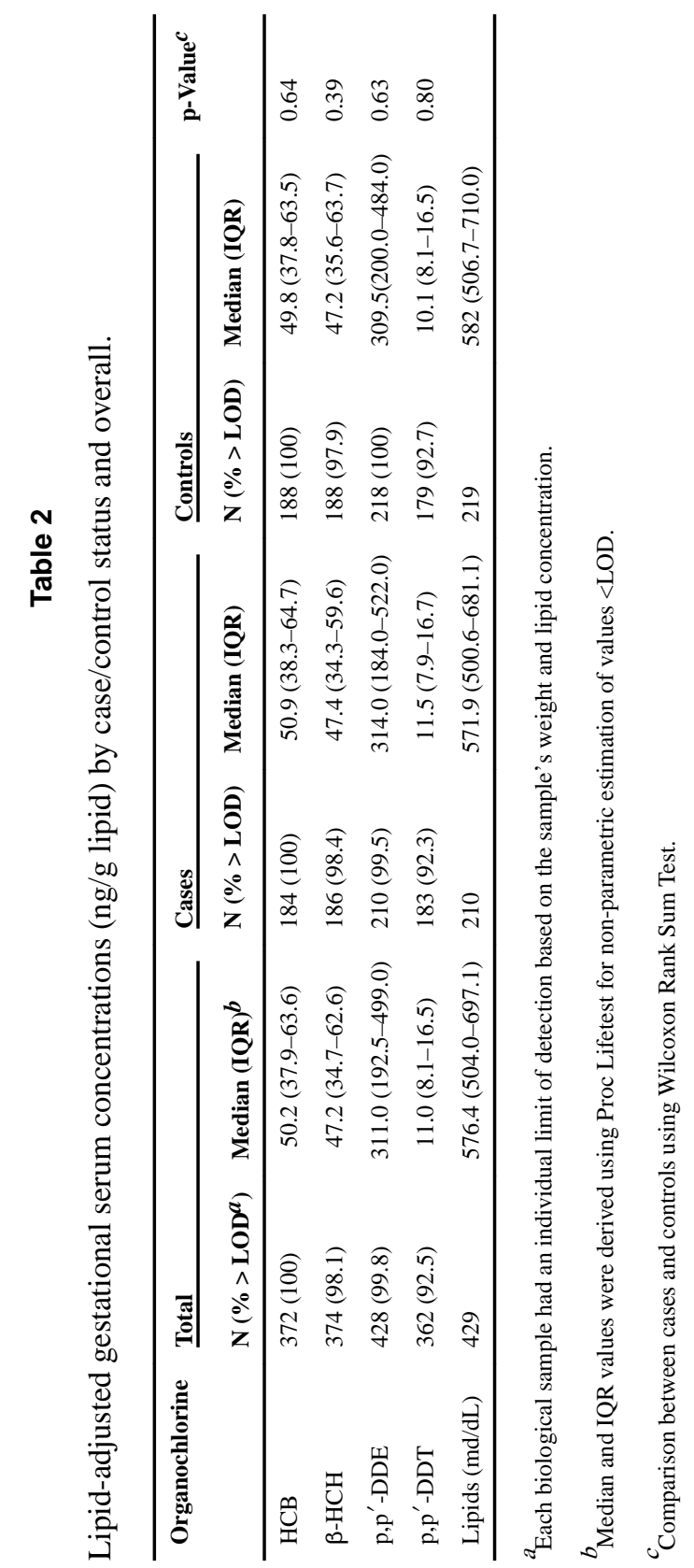




\section{Table 3}

Association between lipid-adjusted organochlorine gestational serum concentrations (ng/g lipid) and early menarche (logged organochlorine concentration).

\begin{tabular}{|c|c|c|c|}
\hline Organochlorine & Unadjusted OR $(95 \% \mathrm{CI})^{a, e}$ & Adjusted OR $(95 \% \mathrm{CI})^{a, e}$ & Adjusted $p$ value \\
\hline $\mathrm{HCB}$ & $1.06(0.67-1.68)$ & $0.93(0.58-1.50)^{b}$ & 0.77 \\
\hline$\beta-\mathrm{HCH}$ & $0.91(0.64-1.29)$ & $0.85(0.59-1.22)^{b}$ & 0.37 \\
\hline $\mathrm{p}, \mathrm{p}^{\prime}-\mathrm{DDE}$ & $0.91(0.70-1.19)$ & & $0.50^{c}$ \\
\hline $\mathrm{p}, \mathrm{p}^{\prime}-\mathrm{DDT}$ & $1.06(0.72-1.54)$ & $0.97(0.65-1.42)^{d}$ & 0.84 \\
\hline
\end{tabular}

${ }^{a}$ Odds of early menarche for a unit increase of logged organochlorine pesticide concentration.

${ }^{b}$ Adjusted for mother's age at menarche.

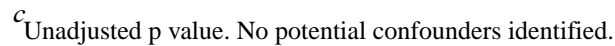

${ }^{d}$ Adjusted for mother's prenatal BMI.

$e^{e}$ Number of cases, number of controls used in both unadjusted and adjusted models: HCB $(184,188) ; \beta-H C H ~(186,188) ;$ PP' $-\mathrm{DDE}$ (210, 218); PP '-DDT $(183,179)$. 


\section{Table 4}

Association between lipid-adjusted organochlorine gestational serum concentrations (ng/g lipid) and early menarche (dichotomous organochlorine concentration).

\begin{tabular}{|c|c|c|c|}
\hline Organochlorine & Unadjusted OR $(95 \% \mathrm{CI})^{f}$ & Adjusted OR $(95 \% \text { CI })^{f}$ & Adjusted p value \\
\hline $\mathrm{HCB}$ & $1.09(0.73-1.64)^{a}$ & $0.98(0.65-1.49)^{a, c}$ & 0.93 \\
\hline$\beta-\mathrm{HCH}$ & $0.98(0.65-1.47)^{a}$ & $0.92(0.61-1.39)^{a, c}$ & 0.69 \\
\hline $\mathrm{p}, \mathrm{p}^{\prime}-\mathrm{DDE}$ & $1.02(0.70-1.49)^{a}$ & & $0.92^{d}$ \\
\hline $\mathrm{p}, \mathrm{p}^{\prime}-\mathrm{DDT}$ & $1.22(0.80-1.85)^{a}$ & $1.13(0.74-1.73)^{a, e}$ & 0.57 \\
\hline Oxychlor & $0.73(0.46-1.14)^{b}$ & $0.67(0.43-1.07)^{b, c}$ & 0.09 \\
\hline T-nona & $1.05(0.69-1.62)^{b}$ & $0.99(0.64-1.55)^{b, e}$ & 0.99 \\
\hline$\Upsilon-\mathrm{HCH}$ & $0.83(0.53-1.32)^{b}$ & & $0.43^{d}$ \\
\hline
\end{tabular}

${ }^{a}$ Odds of early menarche for in utero exposure $\geq$ median compared to <median using distribution of controls.

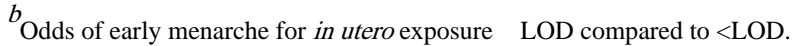

${ }^{c}$ Adjusted for mother's age at menarche.

$d_{\text {Unadjusted p value. No potential confounders identified. }}$

e Adjusted for mother's prenatal BMI.

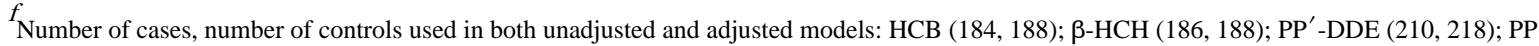
'-DDT (183, 179); oxychlordane (194, 197); trans-nonachlor (189, 196); ؟-HCH (218, 229). 


\section{Table 5}

Association between lipid-adjusted organochlorine gestational serum concentrations (ng/g lipid) and early menarche (organochlorine concentration categorized in quartiles; $<25$ th, $\geq 25$ th $-<50$ th, 250 th $-<75$ th, and $\geq 75$ th percentiles).

\begin{tabular}{|c|c|c|c|}
\hline Organochlorine & Unadjusted OR $(95 \% \mathrm{CI})^{a, e}$ & Adjusted OR $(95 \% \mathrm{CI})^{a, e}$ & Adjusted $p$ value \\
\hline \multicolumn{4}{|l|}{ НCB } \\
\hline$<25$ th & 1 (reference) & 1 (reference) & \\
\hline$\geq 25$ th $-<50$ th & $0.92(0.51-1.64)$ & $0.98(0.54-1.77)^{b}$ & 0.99 \\
\hline$<50$ th -250 th & $1.07(0.60-1.89)$ & $1.06(0.59-1.90)^{b}$ & 0.67 \\
\hline$\geq 75$ th & $1.02(0.57-1.82)$ & $0.89(0.49-1.60)^{b}$ & 0.59 \\
\hline \multicolumn{4}{|l|}{$\beta-\mathrm{HCH}$} \\
\hline$<25$ th & 1 (reference) & 1 (reference) & \\
\hline$\geq 25$ th $-<50$ th & $0.71(0.39-1.26)$ & $0.73(0.40-1.32)^{b}$ & 0.53 \\
\hline$<50$ th -250 th & $0.91(0.52-1.58)$ & $0.89(0.51-1.56)^{b}$ & 0.67 \\
\hline 275 th & $0.76(0.43-1.35)$ & $0.71(0.40-1.27)^{b}$ & 0.42 \\
\hline \multicolumn{4}{|l|}{$\mathrm{p}, \mathrm{p}^{\prime}-\mathrm{DDE}$} \\
\hline$<25$ th & 1 (reference) & & \\
\hline$\geq 25$ th $-<50$ th & $0.64(0.37-1.10)$ & & $0.17^{c}$ \\
\hline$<50$ th -250 th & $0.73(0.43-1.25)$ & & $0.53^{c}$ \\
\hline$\geq 75$ th & $0.93(0.56-1.57)$ & & $0.40^{c}$ \\
\hline \multicolumn{4}{|l|}{$\mathrm{p}, \mathrm{p}^{\prime}-\mathrm{DDT}$} \\
\hline$<25$ th & 1 (reference) & 1 (reference) & \\
\hline$\geq 25$ th $-<50$ th & $0.56(0.29-1.06)$ & $0.53(0.28-1.02)^{d}$ & 0.06 \\
\hline$<50$ th -250 th & $0.99(0.57-1.74)$ & $0.91(0.52-1.60)^{d}$ & 0.41 \\
\hline 275 th & $0.89(0.50-1.60)$ & $0.81(0.45-1.47)^{d}$ & 0.90 \\
\hline \multicolumn{4}{|c|}{ Odds of early menarche for quartiles 225 th $-<50$ th, 250 th $-<75$ th, or $\geq 75$ th compared to $<25$ th. } \\
\hline \multicolumn{4}{|c|}{$b$ Adjusted for mother's age at menarche. } \\
\hline \multicolumn{4}{|c|}{${ }^{c}$ Unadjusted $\mathrm{p}$ value. No potential confounders identified. } \\
\hline \multicolumn{4}{|c|}{$d_{\text {Adjusted for mother's prenatal BMI. }}$} \\
\hline
\end{tabular}

